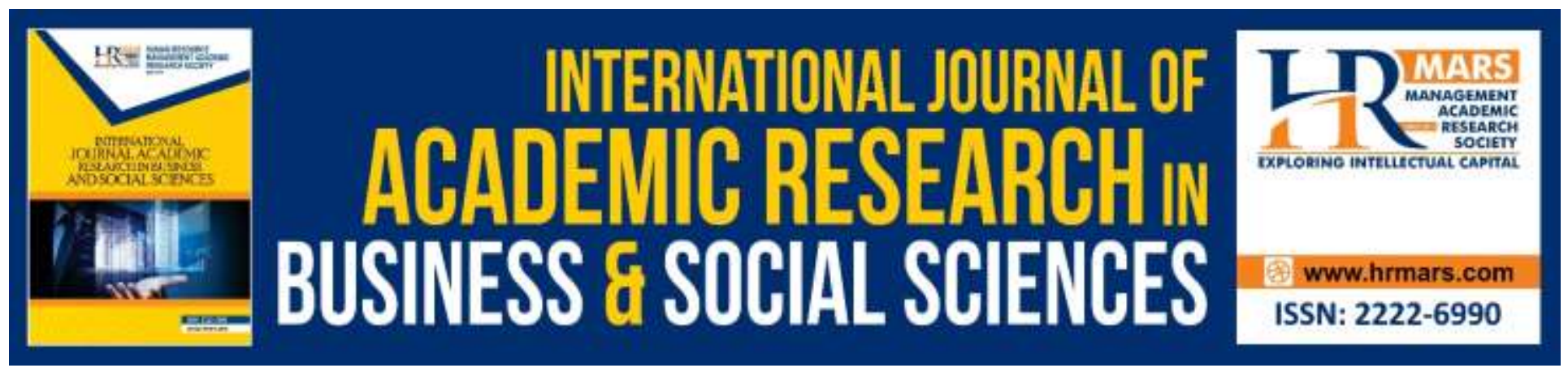

\title{
Constructivist Learning, Vocabulary Learning Strategies and Motivational Theories for English Vocabulary Acquisition Tool Using Cloud Computing
}

Yew Yean Yoong, Sharanjit Kaur, Pong Hon Keat

To Link this Article: http://dx.doi.org/10.6007/IJARBSS/v9-i13/6871

DOI: 10.6007/IJARBSS/v9-i13/6871

Received: 22 March 2019, Revised: 17 April 2019, Accepted: 02 May 2019

Published Online: 23 August 2019

In-Text Citation: (Yoong et al., 2019)

To Cite this Article: Yoong, Y. Y., Kaur, S., \& Keat, P. H. (2019). Constructivist Learning, Vocabulary Learning Strategies and Motivational Theories for English Vocabulary Acquisition Tool Using Cloud Computing. International Journal of Academic Research in Business and Social Sciences, 9(13), 457-470.

Copyright: (C) 2019 The Author(s)

Published by Human Resource Management Academic Research Society (www.hrmars.com) This article is published under the Creative Commons Attribution (CC BY 4.0) license. Anyone may reproduce, distribute, translate and create derivative works of this article (for both commercial and non-commercial purposes), subject to full attribution to the original publication and authors. The full terms of this license may be seen at: http://creativecommons.org/licences/by/4.0/legalcode

Special Issue: Revolutionizing Education: Challenges, Innovation, Collaboration, 2019, Pg. 457 - 470 http://hrmars.com/index.php/pages/detail/IJARBSS JOURNAL HOMEPAGE

Full Terms \& Conditions of access and use can be found at http://hrmars.com/index.php/pages/detail/publication-ethics 


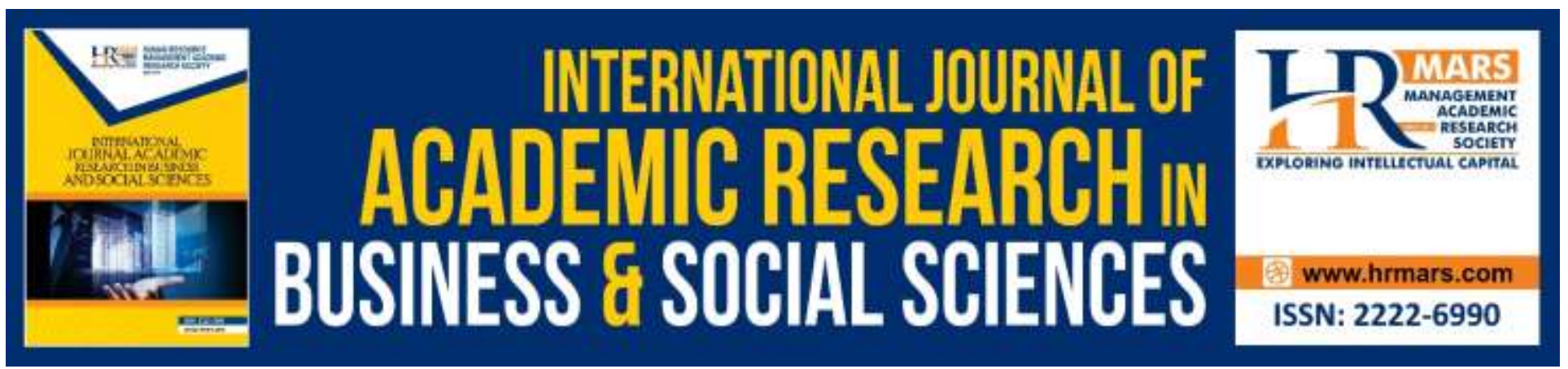

\title{
Constructivist Learning, Vocabulary Learning Strategies and Motivational Theories for English Vocabulary Acquisition Tool Using Cloud Computing
}

Yew Yean Yoong, Sharanjit Kaur, Pong Hon Keat

Centre for Research and Innovation, Quest International University Perak, Plaza Teh Teng Seng, 227, Jalan Raja Permaisuri Bainun, 30250 Ipoh, Perak, Malaysia

Email: yeanyoong.yew@qiup.edu.my, sharanjit.kaur@quip.edu.my

Faculty of Engineering and Information Technology, Southern University College, Jalan Selatan Utama Off, Jalan Skudai - Gelang Patah, 81300 Skudai, Johor, Malaysia

Email: hkpong@gmail.com

\begin{abstract}
English vocabulary learning experience through an individual and collaborative learning environment can be extended using cloud computing technology. The immediate benefits of cloud computing are obvious where cloud-based applications reduce infrastructure and IT costs, increase accessibility and enable collaboration for their users. However, the local students of institutes of higher education (IHE) seldom apply the Web 2.0 technology in vocabulary learning tools because these tools do not focus on learners' needs. Besides, they also do not integrate any student-centred approach, vocabulary learning strategies or motivational techniques to cater for various learning styles. With the help from the literatures, this paper focuses on formulating the conceptual framework in developing a cloud-based student-centred vocabulary learning tool which is named as VocabBook. Since the cloud-based web applications can be run on any Internet browsers, this will enable the students to design their own learning time at their convenience. Besides the strategies applied, the gamification technique will also be utilized to motivate the learners to attempt the quizzes to improve the learning capabilities. The findings from the literature will be helpful for the IHE students to elevate their learning styles. One of the biggest advantages of cloud-based computing is the Software-as-a-Service (SaaS) model. Many software programs are now available either free or on a low-cost subscription basis, which substantially lowers the cost of essential applications for students. Finally, the paper presents UML-based Web Engineering (UWE) that will be used to visualize the design stage of the VocabBook tool proposed for the student-centred learning approach.
\end{abstract} Keywords: Cloud Computing, Collaborative Learning, Motivation, Student-Centred Approach

\section{Introduction}


Learning vocabulary of a language is one of the keys to master a particular language. According to Fisher and Frey (2014); Iliopoulou \& Anastasiadou (2014), vocabulary is not an isolated skill, but it is the core of literacy of a language. Vocabulary does not merely refer to a single unit of word and meaning, it relates to a lexicon or phrase of words that people use for daily and meaningful communication. Academic vocabulary words which are commonly abstract, nuanced, and densely packed with meaning appear much in literary texts or popular media (Townsend \& Kiernan, 2015).

Web 2.0 supports user-generated content that facilitates websites to inter-operate in different types of systems and devices. Cloud computing relies on Web 2.0 to deliver virtualized materials as a service in interactive webpages (AlCattan, 2014). In recent years, cloud computing has been popularly applied in the academic field to enrich the learners' learning experience via a collaborative and individual learning platform (Barhate \& Narale, 2015; Yu, Izhar, Rafedzi, Husin, \& Mokhtar, 2018). In the e-learning (electronic learning) domain, interactive learning and sharing of resources are promoted by using cloud computing which can offer dynamic contents to different learner needs (Barhate \& Narale, 2015). All these cloud-based academic resources can be kept in the cloud server safely.

\section{Background of Study}

There is a need to make web-based learning systems more student-centred in its design and development (Hannafin \& Hannafin, 2010; McLoughlin \& Lee, 2010; Lee, Srinivasan, Trail, Lewis \& Lopez, 2011). According to Ogle and Correa-Kovtun (2010), there is little research to lead teachers on encouraging English language learners (ELLS) to develop their reading skills on the informational texts and learn new academic words which are crucial to study.

Meanwhile, there are a few evidences in the usefulness of online education for developing knowledge and skills in Malaysia and Singapore (Luo, Boland \& Chan, 2013). According to Thang, Nambiar, Wong, Jaafar, and Amir (2015), local institutes of higher education (IHE) students more frequently use Web 2.0 technological tools for social networking but less commonly apply web technologies for learning English. Facebook and emails are preferred sites as their English learning aids whereas Web-based English self-practices are rarely integrated into their educational learning purposes.

Vocabulary words which are predefined in the web-based vocabulary learning websites, are not suitable for IHE learners. For instance, the author explained that the www.britishcouncil.my website predetermines the vocabulary items in the word games that may not be appropriate for every learner. Vocabulary learning might not take place when the vocabulary list is selected by someone else as student-centred approach highlights that the learner should choose his own vocabulary during reading (Mukoroli, 2011). Johnson (2016) argued that personal vocabulary journals are useful for a learner to enter his chosen new vocabulary items which include dictionary definitions, reflections and student drawings. Investigation in this study will be based on the following research question on an interactive web-based English vocabulary learning tool:

- What are the theories used for formulating a conceptual framework for developing the learning tool? 
INTERNATIONAL JOURNAL OF ACADEMIC RESEARCH IN BUSINESS AND SOCIAL SCIENCES

Vol. 9, No. 13, Special Issue: Revolutionizing Education: Challenges, Innovation, Collaboration., 2019, E-ISSN: 2222-6990 @ 2019 HRMARS

\section{Related Works}

A comparison study of online vocabulary acquisition tools are summarized in Table 2.1. Among the tools reviewed are Lexipedia (Avinash \& Samson 2016; Chen, 2013), Snappy Words (Avinash \& Samson 2016), Quizlet (Imrie, 2014), vocabsushi (Angalakuduru, 2014), vocabulary.com (Angalakuduru, 2014; Bromley, 2004), My Dictionary (Usami, Eguchi, Ozaki \& Adachi, 2015) and British Broadcasting Corporation (BBC) (Gibbs, 1992a \& Hughes, 2002). Appendix A presents the features of each vocabulary acquisition tool as well as its strengths and limitations to review for the proposed study. The authors used the information for proposing the theoretical framework which will be discussed in the next section.

\section{The Importance of Cloud Computing in Web 2.0}

Cloud computing which is associated with Web 2.0 offers several advantages in e-learning. The advantages include cost reduction, cloud collaboration for sharing resources and communicating with other learners, and facilitating users to control and access data for higher education platform (Barhate \& Narale, 2015). Higher education academic resources such as vocabulary lists which are saved in cloud storage can be distributed to different channels with minimum production cost

Software-as-a-Service (SaaS) is the most frequent cloud computing service model employed by IHE (Akande \& Van Belle, 2014). This model shows positive result in IHE learners' academic achievement (Akande \& Van Belle, 2016; Alsaeed \& Saleh, 2015). In recent years, IHE favours the SaaS model as it opens up a conducive channel that inspire learning on cloud-based applications. It facilitates collaborative learning at IHE students' convenience.

Yip and Kwan (2006) revealed that undergraduate students preferred online vocabulary games over traditional activity-based settings. This is due to the reason that digital vocabulary games provide dynamic content that assists students to remember the new lexicons for a longer period of time and retrieve more lexicons as compared to classroom vocabulary learning activities.

VocabBook adopts the SaaS model to promote student-centred and collaborative lexicon learning. The vocabulary database of VocabBook is protected to ensure the resources are safely kept in cloud database. Learners can access their vocabulary sets and peer vocabulary sets through VocabBook cloud application by entering their username and password. Meanwhile, the database can be shared among the users for online gaming purpose to obtain the effective learning outcome from any location without paying any fees, shifting or reprinting cost.

\section{Web Engineering Method}

Web engineering is a subset of software engineering (Murugesan, Deshpande, Hansen \& Ginige, 2001) which highlights the use of engineering principles to create quality web-based applications according to user needs (Viniski, Grzebielucka \& Ferrasa, 2014). UWE is an extension of the UML (Unified Modelling Language) metamodel in which the original elements of the UML remain the same within the UWE (Koch \& Kraus, 2003). It consists of development stages, system's views and aspects.

UWE encompasses the whole life-cycle of web application development and comprises requirements modelling phase, conceptual modelling phase, navigation modelling phase and presentation modelling phase (Wakil, Jawawi \& Safi, 2015; Hamdy, Elsoud \& El-Halawany, 2011). Requirement models and architecture models are emphasized to specify the development of the web 
INTERNATIONAL JOURNAL OF ACADEMIC RESEARCH IN BUSINESS AND SOCIAL SCIENCES

Vol. 9, No. 13, Special Issue: Revolutionizing Education: Challenges, Innovation, Collaboration., 2019, E-ISSN: 2222-6990 @ 2019 HRMARS

application (Viniski, Grazebielucka, Ferrasa \& 2014). UML is useful in different stages of KBS development to solve business system problems in a small financial company (Chung \& Pak, 2006).

\section{Constructivist Theory}

Constructivist theory on language study explained that the individual internalizes social activities with more language use, others lead to behavioural transformations and bridges early, and later results in individual language development (Vygotsky, 1978). The central notion of his theory is zone of proximal development (ZPD). ZPD refers to the distance between what a student can do with and without help (Vygotsky, 1978). Fig. 1 illustrates how a learner can master a skill and strategy which he will then use through peer interaction within his ZPD (McLeod, 2014). ZPD focused on student-centred learning where learning outcomes can be achieved through guided practice. Vygotsky (1978) particularly viewed adult as a peer who is more likely to accomplish a task by collaboration. He promoted lifelong learning with his constructivist theory to develop student's higher mental function. Learners' language knowledge and skills are constructed with guided learning or during game execution with peers in a group.

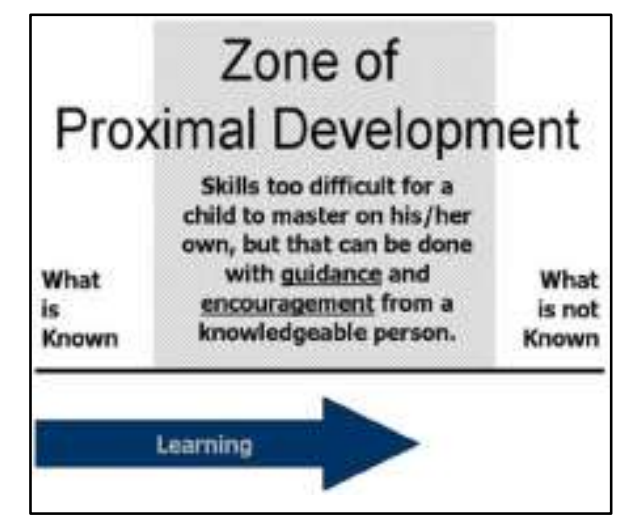

Fig. 1 Zone of Proximal Development (McLeod, 2014)

Learner knowledge is developed internally and externally (Vygotsky, 1978). Student-centred learning approach which is based on constructivist learning theory highlights the student's role in constructing knowledge. Vygotsky pointed out that learning takes place when education model concentrates on the students' interest rather than on the needs of the outside world (Ostoff, 2012). The theory revealed that student language development depends on self-chosen learning items and practises the items within a collaborative learning group or with the assistance from more proficient students.

The student-centred model proposed that second language vocabulary acquisition begins with students managing their own learning and are independent to choose glossary words for themselves based on their personal interest and needs (Larrotta, 2011). Explicit study on self-made lexicon lists with interactive word practice enhances learners' second language proficiency in English (Spiri, 2007). Therefore, Hopkyns and Nicoll (2013) introduced that learners need to select the new words they are interested to learn as the words are personalized and promotes information retention. 
Student-centred e-learning can engage students in dynamic learning process through active learning and group connection at multiple levels (Morris \& Faulk, 2012). The student-centred elearning strategy recommended electronic word diagrams that are very effective for vocabulary enhancement (Hopkyns \& Nicoll, 2013). The word diagrams are mostly favoured by the visual learner when they can be used to develop thoughts and factors bridging to an idea. Web diagrams make associations that specify the word form and its meaning which are impressed in the students' mind (Tickoo, 2003).

Digital graphic organizers increase the value of the traditional graphic organizers. Hutchison and Colwell (2015) emphasized that learners can share their digital word mappings among the group members in a class blog or website for supporting each other to construct lexical knowledge.

Student-centred vocabulary learning is enriched by digital graphic organizers to structure the information of learner-selected words to facilitate understanding. Electronic graphic organizers promote lexicon learning by depicting the connections among the semantic, syntax and usage of a learners' self-selected vocabulary. Such digital drawing is highly popular in group learning. Hence, student-centred e-learning approach through electronic graphic organizers will be applied to formulate the conceptual framework in developing VocabBook to facilitate second language (L2) learners in autonomous and constructivist word learning (Fig. 2).

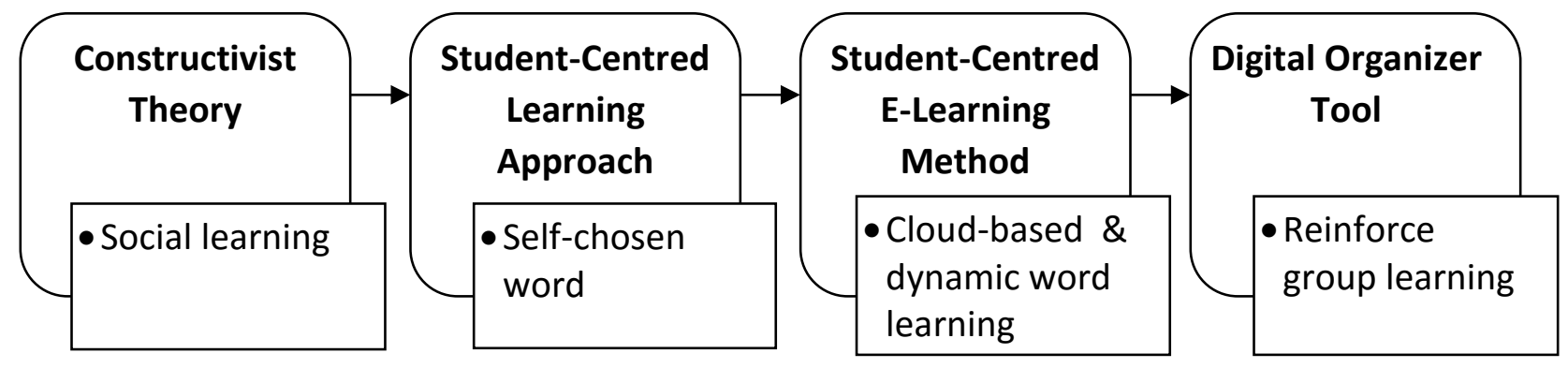

Fig. 2 Application of Constructivist Theory in VocabBook

\section{Effective Vocabulary Learning Strategies}

Research on vocabulary acquisition strategies were carried out to help the learners to develop their vocabulary (Nyikos \& Fan, 2007). Choo, Lin and Pandian (2012) argued that the implicit and explicit strategies should be included into the teaching and learning of new vocabulary. The meaning of new vocabulary can be acquired unconsciously through repeated exposure to the words; and explicitly through planned instruction.

Explicit learning involves applying word learning strategies to consolidate a new word by consulting a dictionary and through note taking and word-play activities. Moreover, learners who use multiple vocabulary learning strategies are more effective in vocabulary acquisition (Johnson and Heffernan, 2006). Word learning strategies applicable in a reading context either from printed material or hypertext include dictionary use, utilization of contextual clues, note taking and practice (Gu, 2003).

According to Oxford (1990), the learner concludes the meaning of a new word by determination and social strategies. Then, the learners need to consolidate the meaning of the word by using cognitive, metacognitive, memory and social strategies. Hence, Schmitt (1997) categorized 
the vocabulary learning strategies into determination, social, memory, cognitive and metacognitive. The learners need to determine the meaning of new words and then consolidate the meaning of the word when they encounter the word again.

As a result, Schmitt (1997) proposed a theory of vocabulary learning strategies which enumerates numerous effective techniques for implementing these five vocabulary learning strategies. Analysing the part of speech, guessing the word from textual context, creating a word list, using a monolingual and bilingual dictionary are the techniques introduced in the determination strategy. Discovering new meaning through study and practice in a group are some popular techniques applied in social strategy. Vocabulary memorization strategy encompasses connecting the word to its synonyms and antonyms, applying words in sentences and using the words in idioms. Cognitive strategy comprises creating word lists, taking notes and keeping a vocabulary notebook. Testing oneself with word tests and continuous study are utilized in meta-cognitive strategy in vocabulary learning.

The recognition of the role of Schmitt's five vocabulary learning strategies has continued to grow. Among the researches discussed in this subject matter was a research by Rossiter, Abbott and Kushnir (2016) who reported that at least $75 \%$ of adult ESL educators teach new lexicon by using the vocabulary in an example sentence, providing a simple definition, asking students for definitions, writing the word, providing a synonym and discussing underlying meanings of words. Furthermore, the researchers also revealed that the most useful word learning strategies rated by educators were guessing the word from context, working in pairs or groups, and choosing their own words to learn. However, ESL Malaysians students rarely apply the vocabulary learning strategies and a few popular strategies used in the research study are using monolingual dictionary, guessing from the context, and studying through the English language media. (Azadeh Asgari \& Ghazali Mustapha, 2011).

Individual English vocabulary pool enhancement requires five explicit vocabulary acquisition strategies. To achieve the research objective, the five recommended strategies are incorporated into electronic graphic organizers for understanding and acquiring a new English word effectively. Hence, Fig. 3 presents some popular vocabulary learning techniques which include building a word list, applying a dictionary, practicing a word use in a group, matching a word to its synonym and antonym, and assessing oneself through vocabulary tests that will be applied in VocabBook.

Theory of Vocabulary Learning Strategies

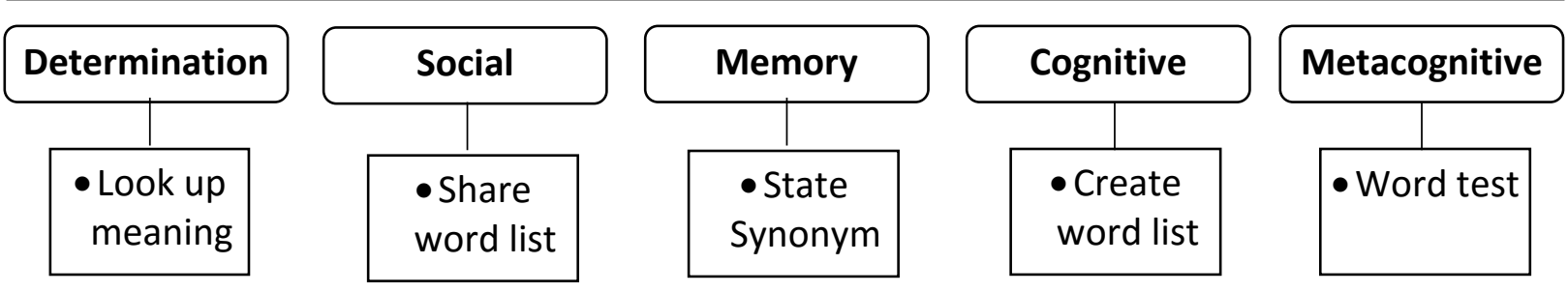

Fig. 3 Application of Theory of Vocabulary Learning Strategies

\section{Language Learning Motivation}

Gardner (1985) defined that L2 motivation as a "combination of effort plus desire to achieve the goal of learning the language plus favorable attitudes toward learning the language." (p.10) The motivational theory named ARCS model describes motivational aspects and instructional design to 
sustain students' motivation to learn (Keller, 2000). Keller divided the model into attention (A), relevance (R), confidence (C) and satisfaction (S) which is based on motivational concepts and characteristics. Attention is to help to sustain students' attention and prevent them from tuning out. Relevance is to connect the learning content to learners' interests and styles. Confidence is to guide students to gain positive learning experience for success. Satisfaction is to grade learning outcome by providing intrinsic and extrinsic rewards.

The two types of motivation are intrinsic motivation and extrinsic motivation. Intrinsic motivation uses self-determination theory which stresses that learner behaviours are selfdetermined and self-motivated (Moy, Renshaw \& Davids, 2016). In contrast, extrinsic motivation expected external incentives (Schmid, \& Whyte, 2014). According to Kuo and Chuang (2016), gamification can motivate and engage students in online academic learning.

The gamification approach utilizes motivation theories that involve intrinsic and extrinsic motivation in e-learning environments (Shi, Cristea, Hadzidedic, Dervishalidovic, 2014). Brigham (2015) suggested that gamification applies game elements that generate awards to the users such as points, badges and leaderboards to motivate students intrinsically and extrinsically. Gamification facilitates users in studying a second language be increasing motivation towards a learning approach that enhances weak areas and builds skills (Flores, 2015).

To achieve the research objective, a motivational model, crucial in supporting vocabulary learning is an important component. The graphic organizer is an appropriate tool used in VocabBook as it is selected as an e-learning tool in student-centred learning and it can be used to fulfill the Attention aspect in the ARCS motivational model as well. As discussed earlier, it is an interesting visual tool which can arouse student's interest.

Motivational level is enhanced by encouraging students to look up the meaning of a word which is relevant to his current subject area. Vocabulary practice and tests are methods which can boost students' confidence in using lexical items in the four linguistic skills in daily verbal and nonverbal communication. A gamified system that uses levels and scores for rewarding students promotes intrinsic and extrinsic motivation. Gamification is a feature strongly recommended in designing VocabBook as it can help students attain satisfaction. Fig. 4 illustrates the application of Keller's ARCS motivational model in VocabBook.

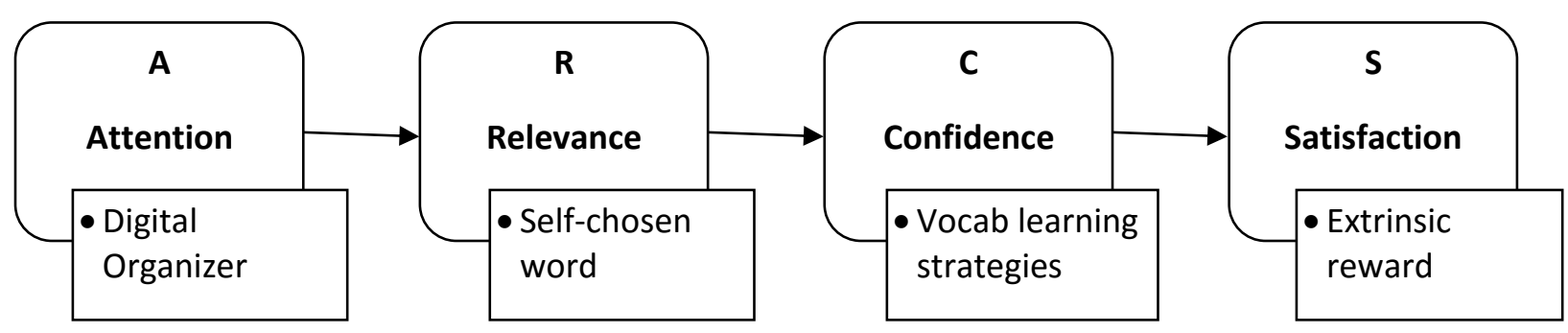

Fig. 4 Application of Motivational Theory in VocabBook

\section{Theoretical Framework}

This theoretical framework supporting this research study is an incorporation of motivational theory, constructivist learning theory and theory of vocabulary learning strategies. The selected theories have been included to form the theoretical framework that underpin VocabBook which serves as a stage to enhance learners' language performance and forms the groundwork for the 
development of the web interface design and its functionality. The theoretical framework for this research study is presented in Fig. 5.

The learner-centred approach supported by constructivist learning theory is to enhance individual word performance through self-determination and collaborative vocabulary learning. Vocabulary learning strategies streamline learners in improving their performance. Motivational theory sustains learner interest by introducing a scoring system.

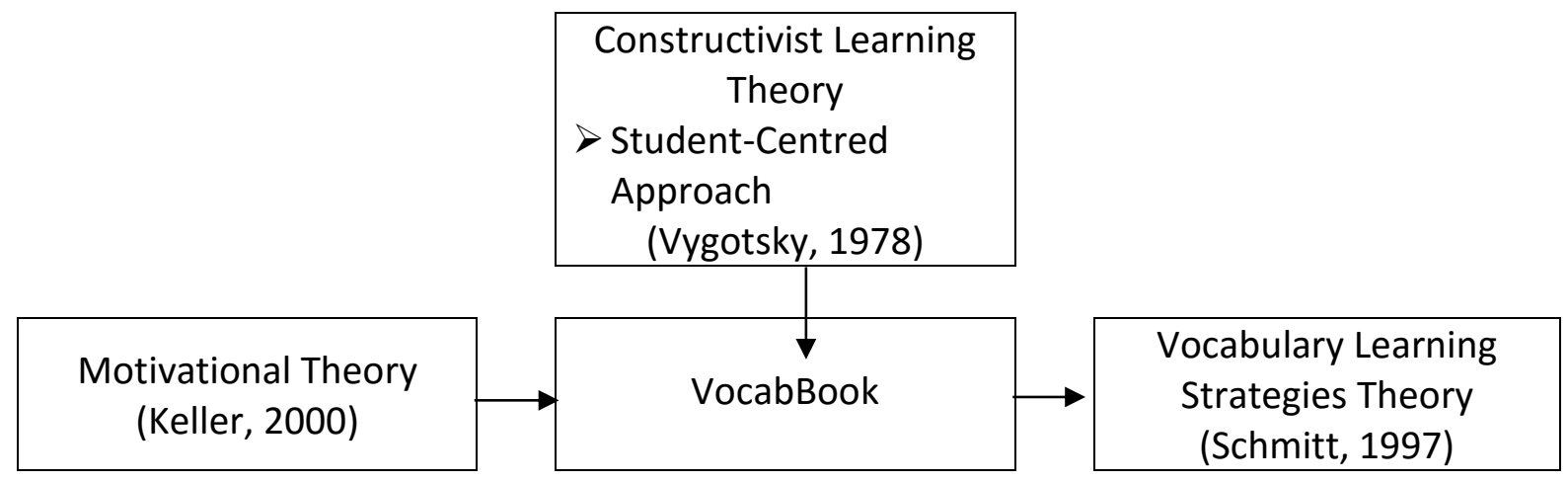

Fig. 5 Theories Underpinning This Study

\section{Conceptual Framework}

Fig. 6 demonstrates the conceptual framework that serves as the foundation of work in this research design. The framework will be used to design, develop, implement and evaluate VocabBook as well. The framework is formed based on Constructivist Theory, Vocabulary Learning Strategies Theory and Motivational Theory, which is seen as influencing effectiveness of vocabulary learning using VocabBook. Meanwhile, the UWE method is applied as a web engineering method to analyse and design VocabBook as a learning tool in this research. 


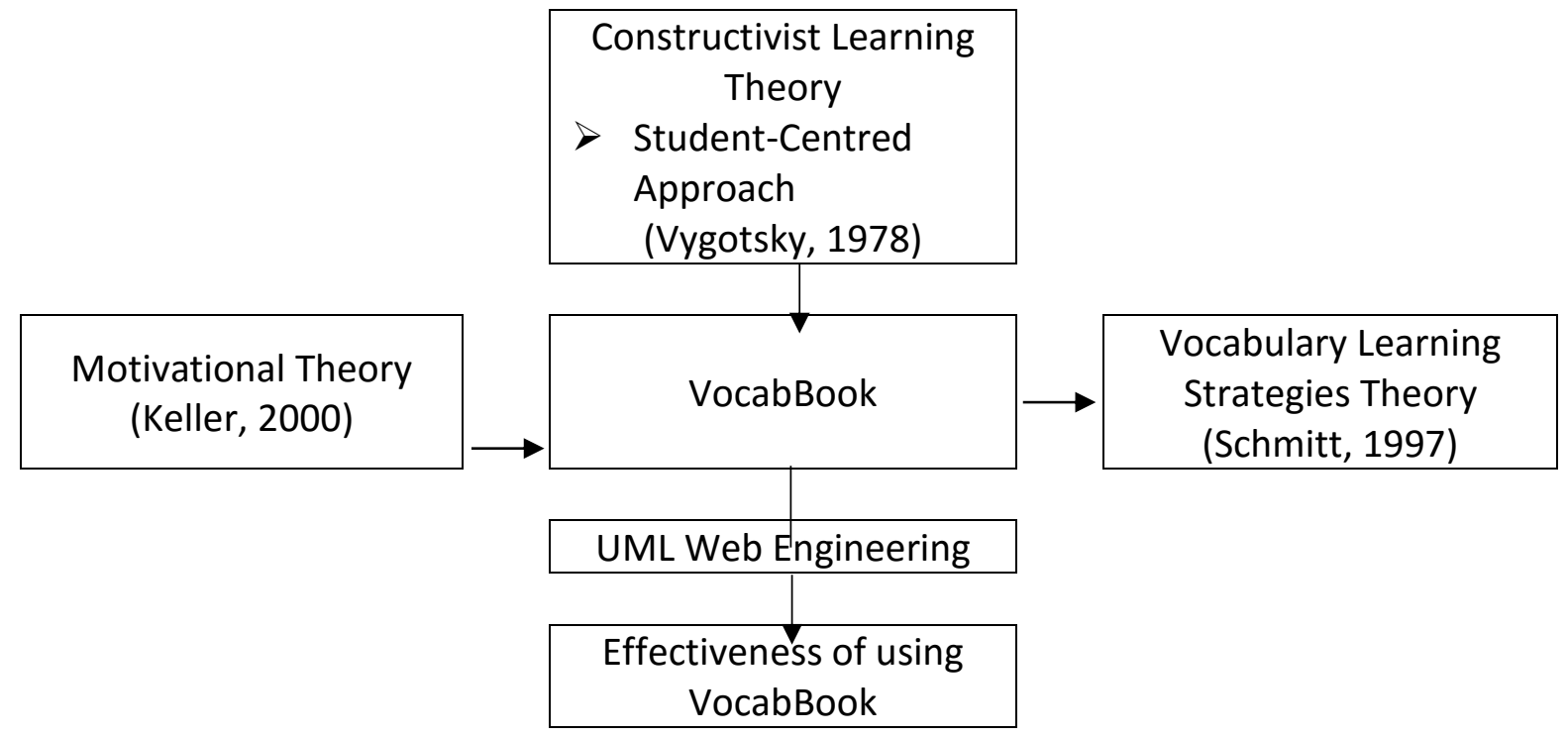

Fig. 6: Conceptual Framework

\section{Discussion}

The research objective of this study is to formulate a conceptual framework for developing a cloud-based student-centred vocabulary learning tool, named VocabBook. This objective has been achieved through reviewing of literatures on the topics covering previous studies on web-based English vocabulary learning tool, cloud computing web engineering method, constructivist theory, effective vocabulary learning strategies, language learning motivation. The outcome of reviews was presented using the proposed theoretical framework and then the conceptual framework. The future work of this study is to design and develop a prototype of VocabBook for IHE students. This will then lead to evaluate the functionalities and ease-of-use of VocabBook. These two objectives will focus on developing VocaBook which is a prototype of vocabulary learning web application and evaluate the functionality and usability of the web application.

\section{Acknowledgements}

This research work is supported by Quest International University Perak (QIUP) under the student scholarship scheme. The author would like to thank the management of Faculty of Science and Technology of QIUP in making this study a success.

\section{References}

Akande, A. O., \& Van Belle, J. P. (2014). Cloud computing in higher education: A snapshot of software as a service. Paper presented at International Conference on IEEE (pp 1-5). Adaptive Science \& Technology (ICAST).

Akande, A. O., \& Van Belle, J. P. (2016). The use of software as a service by students in higher education institutions: a systematic literature review. Paper presented at the Proceedings of the 18th Annual International Conference on Electronic Commerce: e-Commerce in Smart connected World (p. 1). ACM. 
INTERNATIONAL JOURNAL OF ACADEMIC RESEARCH IN BUSINESS AND SOCIAL SCIENCES

Vol. 9, No. 13, Special Issue: Revolutionizing Education: Challenges, Innovation, Collaboration., 2019, E-ISSN: 2222-6990 @ 2019 HRMARS

AlCattan, R. F. (2014). Integration of cloud computing and web2. 0 collaboration technologies in elearning. arXiv preprint arXiv:1406.5020.

Alsaeed, N., \& Saleh, M. (2015). Towards Cloud Computing Services for Higher Educational Institutions: Concepts \& Literature Review. Paper presented at the International Conference on IEEE (pp. 1-7). Cloud Computing (ICCC).

Angalakuduru, A. D. J. (2014). Analysis of the use of call applications for teaching academic vocabulary by the ESL teachers in the technical institutes in India. Research Journal of English Language and Literature, 2(4), 159-167.

Avinash, M. R., \& Samson, R. (2016). Use of puzzle solving games to teach English. Indian Journal of Science and Technology, 9(15).

Alamri, A.M. (2018). Strategic Management Accounting and the Dimensions of Competitive Advantage: Testing the Associations in Saudi Industrial Sector, International Journal of Academic Research in Accounting, Finance and Management Sciences 8 (2): 48-64.

Asgari, A., \& Mustapha, G. B. (2011). The type of vocabulary learning strategies used by ESL students in University Putra Malaysia. English language teaching, 4(2), 84-90.

Barhate S. M., \& Narale S. (2015) Cloud based teaching and learning environment for smart education. International Journal on Recent and Innovation Trends in Computing and Communication, 3(2), 38-41.

Brigham, T. J. (2015). An introduction to gamification: adding game elements for engagement. Medical reference services quarterly, 34(4), 471-480.

Bromley, K. (2004). Rethinking vocabulary instruction. Language and Literacy Spectrum, 14, 3-12.

Chen, X. (2013). Virtual Team Collaboration in Pre-Service Teacher Education. Paper presented at the Society for Information Technology \& Teacher Education International Conference (pp. 3088-3096) on Association for the Advancement of Computing in Education. AACE.

Choo, L. B., Lin, D. T. A., \& Pandian, A. (2012). Language learning approaches: A review of research on explicit and implicit learning in vocabulary acquisition. Procedia-Social and Behavioral Sciences, 55, 852-860.

Chung, W. W., \& Pak, J. J. (2006). A case study: using UML to develop a knowledge-based system for supporting business systems in a small financial institute. International Journal of Computer Integrated Manufacturing, 19(1), 59-68.

Fan, M., \& Nyikos, M. (2007). A review of vocabulary learning strategies: Focus on language proficiency and learner voice. Oxford: Oxford University Press.

Fisher, D., \& Frey, N. (2014). Content area vocabulary learning. The Reading Teacher, 67(8), 594599.

Flores, J. F. F. (2015). Using gamification to enhance second language learning. Digital Education Review, (27), 32-54.

Gardner, R. C., Lalonde, R. N., \& Moorcroft, R. (1985). The role of attitudes and motivation in second language learning: Correlational and experimental considerations. Language learning, 35(2), 207-227.

Gibbs, G. (1992a) Control and independence, in Gibbs, G. and Jenkins, A. (Eds.) Teaching large classes in higher education: How to maintain quality with reduced resources, pp. 37-62 London: Kogan Page. 
Gu, P. Y. (2003). Vocabulary learning in a second language: Person, task, context and strategies. TESL-EJ, 7(2), 1-25.

Hamdy, K. E., Elsoud, M. A., \& El-Halawany, A. M. (2011). UML-based web engineering framework for modeling web application. Journal of Software Engineering, 5(2), 49-63.

Hannafin, M. J., \& Hannafin, K. M. (2010). Cognition and student-centered, web-based learning: Issues and implications for research and theory Learning and instruction in the digital age (pp. 11-23): Springer.

Hopkyns, S., \& Nicoll, T. (2013). A student-centered approach to vocabulary building using Popplet, Pages and Puppet Pals. Learning and Teaching in Higher Education: Gulf Perspectives, 10(2).

Hughes, P. (2002). Developing independent learning skills, paper presented at the 2nd Annual Skills Conference 'Implementing skills development in higher education: reviewing the territory', University of Hertfordshire.

Hutchison, A., \& Colwell, J. (2015). Bridging technology and literacy: Developing digital reading and writing. London: Rowman and Littlefield Publishers.

Imrie, A. C. (2014). Using Quizlet flashcards to study vocabulary. Paper presented at Proceedings of the 19th TESOL Arabia Conference: From KG to College to Career (pp. 26-35).

Johnson, A., \& Heffernan, N. (2006). The short readings project: A CALL reading activity utilizing vocabulary recycling. Computer Assisted Language Learning, 19(1), 63-77.

Johnson, R. A. (2016). How can embedding critical literacy practices through the use of text sets foster a growth mindset in a first grade classroom?

Keller, J. M. (2000). How to integrate learner motivation planning into lesson planning: The ARCS model approach. VII Semanario, Santiago, Cuba, 1-13.

Koch, N., \& Kraus, A. (2003, July). Towards a common metamodel for the development of web applications. Paper presented at the International Conference on Web Engineering (pp. 497506). Springer Berlin Heidelberg.

Kuo, M. S., \& Chuang, T. Y. (2016). How gamification motivates visits and engagement for online academic dissemination-An empirical study. Computers in Human Behavior, 55, 16-27.

Lee, S. J., Srinivasan, S., Trail, T., Lewis, D., \& Lopez, S. (2011). Examining the relationship among student perception of support, course satisfaction, and learning outcomes in online learning. The Internet and Higher Education, 14(3), 158-163.

Luo, J., Boland, R., \& Chan, C. H. (2013). How to Use Technology in Educational Innovation. The Academic Medicine Handbook (pp. 117-123). Springer, New York.

McLeod, S. (2014). Lev Vygotsky. Simply Psychology. Retrieved from https://www.simplypsychology.org/vygotsky.html.

McLoughlin, C., \& Lee, M. J. (2010). Personalised and self regulated learning in the Web 2.0 era: International exemplars of innovative pedagogy using social software. Australasian Journal of Educational Technology, 26(1).

Morris, A. H., \& Faulk, D. R. (2012). Transformative Learning in Nursing: a Guide for Nurse Educators. New York: Springer Publishing Company.

Moy, B., Renshaw, I., \& Davids, K. (2016). The impact of nonlinear pedagogy on physical education teacher education students' intrinsic motivation. Physical Education and Sport Pedagogy, 21(5), 517-538. 
INTERNATIONAL JOURNAL OF ACADEMIC RESEARCH IN BUSINESS AND SOCIAL SCIENCES

Vol. 9, No. 13, Special Issue: Revolutionizing Education: Challenges, Innovation, Collaboration., 2019, E-ISSN: 2222-6990 @ 2019 HRMARS

Mukoroli, J. (2011). Effective vocabulary teaching strategies for the English for academic purposes ESL classroom. Retrieved from http://digitalcollections.sit.edu/ipp_collection/501/

Murugesan, S., Deshpande, Y., Hansen, S., \& Ginige, A. (2001). Web engineering: A new discipline for development of web-based systems. Web Engineering (pp. 3-13). Springer Berlin Heidelberg.

Ogle, D., \& Correa-Kovtun, A. (2010). Supporting English-language learners and struggling readers in content literacy with the "Partner reading and content, too" Routine. The reading teacher, 63(7), 532-542.

Oxford, R. (1990). Language learning strategies. What every teacher should know. Boston: Heinle Publishers.

Rossiter, M. J., Abbott, M. L., \& Kushnir, A. (2016). L2 Vocabulary Research and Instructional Practices: Where Are the Gaps?. Tesl-Ej, 20(1), 1-25.

Schmid, E. C., \& Whyte, S. (Eds.). (2014). Teaching languages with technology: communicative approaches to interactive whiteboard use. London, New York: Bloomsbury Publishing.

Schmitt, N. (1997). Vocabulary learning strategies. In Schmitt, N., \& McCarthy, M. (Eds.) Vocabulary: Description, acquisition, and pedagogy. Cambridge: Cambridge University Press.

Shi, L., Cristea, A. I., Hadzidedic, S., \& Dervishalidovic, N. (2014). Contextual gamification of social interaction-towards increasing motivation in social e-learning. Paper presented at the International Conference on Web-Based Learning (pp. 116-122). Springer International Publishing.

Spiri, J. (2007). Systemic online study of frequency list vocabulary. Paper presented at the Proceedings of the Third International Online Conference on Second and Foreign Language Teaching and Research-March.

Thang, S. M., Jaafar, N. M., Nambiar, R. M., Amir, Z., \& Wong, F. F. (2014). Are Malaysian undergraduates 'Digital Natives' in the true sense of the word? A quantitative analysis. $3 L$ : Language, Linguistics, Literature, 20(1), 177-191.

Thang, S. M., Nambiar, R. M., Wong, F. F., Jaafar, N. M., \& Amir, Z. (2015). A clamour for more technology in universities: What does an investigation into the ICT use and learning styles of Malaysian 'Digital Natives' tell us?. The Asia-Pacific Education Researcher, 24(2), 353-361.

Tickoo, M. L. (2003) Teaching and Learning English, New Delhi: Orient Longman.

Townsend, D., \& Kiernan, D. (2015). Selecting academic vocabulary words worth learning. The Reading Teacher, 69(1), 113-118.

Usami, H., Eguchi, H., Ozaki, M., \& Adachi, Y. (2015). Development of Web Learning Support System using "My Dictionary" in English Study. Procedia Computer Science, 60, 944-951.

Viniski, A. D., Grzebielucka, F. L., \& Ferrasa, A. (2014). UWE and OOWS: a comparative approach of navigation models for web engineering. Iberoamerican Journal of Applied Computing, 4(3).

Vygotsky, L. (1978). Mind in society: The development of higher psychological processes. Cambridge: Harvard University Press.

Wakil, K., Jawawi, D. N., \& Safi, A. (2015). A comparison of navigation model between UWE and WebML: Homepage development case study. International Journal of Information and Education Technology, 5(9), 650.

Iliopoulou, K., \& Anastasiadou, A. (2014). Redefining schooling: Implementing crosscurricularity to create critical thinkers with viable learning strategies. Multilingual Academic Journal of 
Education and Social Sciences, 2(1), 14-27.

Yoong, Y. Y., Kaur, S., \& Keat, P. H. (2019). Constructivist Learning, Vocabulary Learning Strategies and Motivational Theories for English Vocabulary Acquisition Tool Using Cloud Computing. International Journal of Academic Research in Business and Social Sciences, 9(13), 304-318.

Yip, F. W., \& Kwan, A. C. (2006). Online vocabulary games as a tool for teaching and learning English vocabulary. Educational Media International, 43(3), 233-249.

Yu, H., Izhar, T. A. T., Rafedzi, E. R. K., Husin, N., \& Mokhtar, W. N. H. W. (2018). Information Literacy Development through Resource-Based School Projects: Malaysian Students Experience. International Journal of Academic Research in Progressive Education and Development, 7(3), 211-225. 